\title{
Discussing underrepresentation as a means to facilitating female students' physics identity development
}

\author{
Robynne M. Lock ${ }^{1}$ and Zahra Hazari ${ }^{2}$ \\ ${ }^{1}$ Department of Physics \& Astronomy, Texas A\&M University-Commerce, Commerce, Texas 75429, USA \\ ${ }^{2}$ Department of Teaching \& Learning, Florida International University, Miami, Florida 33199, USA
}

(Received 17 May 2016; published 5 July 2016)

\begin{abstract}
Despite the fact that approximately half of high school physics students are female, only $21 \%$ of physics bachelor's degrees are awarded to women. In a previous study, drawn from a national survey of college students in introductory English courses, five factors commonly proposed to positively impact female students' choice of a physical science career were tested using multivariate matching methods. The only factor found to have a positive effect was the explicit discussion of the underrepresentation of women in physics. In order to explore this further, a case study of the classes of one teacher reported to discuss the underrepresentation of women was conducted. Two classroom underrepresentation discussions were recorded, students and teacher were interviewed, and relevant student work was collected. Analyzing the case study data using a figured worlds framework, we found that discussing the underrepresentation of women in science explicitly creates an opportunity for students' figured worlds of professional and school science to change, and facilitates challenging their own implicit assumptions about how the world functions. Subsequently, the norms in students' figured worlds may change or become less rigid allowing for a new openness to physics identity development amongst female students.
\end{abstract}

DOI: 10.1103/PhysRevPhysEducRes.12.020101

\section{INTRODUCTION}

Physics lags behind other science fields in undergraduate growth rates, as well as in representation of women and minorities. Bachelor's degrees in biology and chemistry are earned by women at $59 \%$ and $49 \%$, respectively, but only $21 \%$ of bachelor's degrees earned in physics are attained by women [1]. Furthermore, in the past 10 years the percentage of women earning bachelor's degrees in physics has not increased and instead seen a small decline after a $23 \%$ representation peak in the early 2000s [2].

Most female students choose not to pursue a physics career before ever beginning college. This is despite the fact that more students, especially female students, are taking high school physics courses than was the case in past decades. For example, White and Tesfaye write, "the number of girls taking physics in U.S. high schools increased $161 \%$ between 1987 and 2009; the number of boys was up $88 \%$ over this same period" [3]. In addition, most female physicists who were part of the International Conference of Women in Physics and completed an AIP email survey $(n=1353)$ reported that they first became interested in physics during their high school careers [4]. Thus, in order to attract more women into the field, it is pertinent that we expand our research on formative

Published by the American Physical Society under the terms of the Creative Commons Attribution 3.0 License. Further distribution of this work must maintain attribution to the author(s) and the published article's title, journal citation, and DOI. experiences for female students during the high school years. To this end, the current paper focuses on understanding how a particular experience previously found to have a positive effect on persistence in a quantitative study, namely, the discussion of underrepresentation [5,6], has been implemented in the classroom and why it may have the effect previously observed.

This study advances the physics education research (PER) literature in a few critical ways. First, it provides a detailed example of how discussions of underrepresentation could be structured in a high school physics class. While the prior quantitative work found a positive effect when students reported having such discussions, it does not provide any insight into how these discussions could be carried out. This particular aspect of the paper may be beneficial to those interested in classroom practice. Second, it furthers our theoretical knowledge of possible mechanisms and explanations of why such discussions may be important for the physics identity development of women. This is important because if we understand why a certain practice impacts students, we can use that understanding in designing interventions that could act in similar ways to impact students. Finally, this work brings a new theoretical perspective to the PER literature (i.e., figured worlds), which has been found to be an important lens for understanding identity development in other fields.

\section{BACKGROUND}

While there have been many hypothesized solutions to increase female interest in physics, few have been shown to 
have consistent positive effects. For example, studies on single-sex education have shown mixed results [6,7]. Our prior work set out to test some of these assertions and hypothesized solutions using a robust quantitative approach (multivariate matching) and the results showed that the discussion of the underrepresentation of women in physics had a positive effect on female students' interest in pursuing a physical science career [6]. However, this prior quantitative research was unable to provide insight into how such discussions transpire and why they might impact female students' attitudes.

Within the gender literature, the topic of physics class discussions has largely focused on differences in the roles or discourse of male and female students as well as differences in teachers' actions, questioning, and/or responses to male and female students. Several studies report male students dominating physics classroom communication during discussions and activities [8-12] with other studies ascribing these gender differences in communication to teacher behaviors such as lack of disciplining (allowing male students to dominate) or uneven or preferential treatment $[13,14]$. Fewer studies have focused on examining the role of particular discussion topics on relevant outcomes for female students.

Stadler et al. found that female students during group discussions used imperatives and instructions less often than male students while raising questions and trying to overcome uncertainties more so [14]. While the female students' approach allowed more negotiation of understanding, it also allowed more guesses and "halfunderstandings" whereas the male students' approach was more concrete and factual. Despite these differences in the ways that female and male students engage in physics discussions, students themselves are not consciously aware of these differences when they enact them. In other words, they are just acting as they typically would with respect to the gender roles they have adopted in society and with respect to physics. Furthermore, when they break out of these gender roles, even when unconsciously doing so, research has found that they are not liked by their peers [15]. These findings are relevant to the current paper because this work deals with bringing gender roles in physics that were previously unconscious to the conscious level.

Female students in Stadler et al.s work also tried to relate the content to their everyday knowledge (using everyday language) and to personal analogies (anthropomorphisms) more often. This work further reveals the importance of making personally relevant connections during discussions for improving female students' perceptions of their physics understanding. Similarly, another study focusing on a new curriculum for teaching nuclear physics topics with an approach that gives value to discussion, alternative perspectives, and the relevance to social and personal issues, found significant positive changes for female students' learning and interest in physics [16]. An unanticipated finding of the research was that students exposed to the new curriculum moved from certainty about what they believed they understood to more reflective awareness of the complexity of issues. This reflective awareness came from more nuanced discussions of socioscientific issues (e.g., radiation and health, economic, environmental, and social risks or benefits of power production, waste management). Similarly, in this study we set out to develop a better understanding of how nuanced discussions about underrepresentation in physics classes might impact female students' perceptions of their place in the social world related to physics and their interest in participating in this social world through a career in physics.

While consciousness of gender issues has been discussed in the broader literature $[17,18]$, there has been little work on this topic in science education. Francis, in a study across subjects of students aged 14 to 16 , found that the majority (75\% total; $66 \%$ of females, $84 \%$ of males) believed there to be no difference in female and male student abilities in general [19]. However, the students still adhered to gendered norms with regards to reporting science amongst their most or least favorite subjects with female students ranking it lower than males for their most favorite, and higher than males for their least favorite. This same trend was not seen for mathematics where there was more blurring of traditional gendered subject lines. While this work differentiated between female and male consciousness of gender differences to some extent, it did not focus specifically on science (or physics) nor did it draw connections between this consciousness and students' interests. We could ask the question: Are the students who become conscious of gender differences in a discipline more or less likely to be interested in the discipline? Are they more or less likely to develop identities? This study begins to explore some of these issues using a physics identity and figured world lens. While the work is not focused on a gender identity lens, i.e., what it means for a student to associate to a certain gender and how they perform their gender, we are interested in how the gender narrative shapes who they believe can be a physicist or a physics person.

\section{THEORETICAL FRAMEWORK}

In the next two sections, we present our theoretical framework drawing on physics identity and figured worlds. This particular framing is appropriate because it guides our understanding of how students see themselves with respect to physics (affecting relevant career choices) as well as the socially constructed world of physics and their place in it.

\section{A. Physics identity}

In order to understand students' career choice we use an identity framework. Identity encompasses many personal 
and social aspects of how students see themselves. However, we focus on the discipline-specific physics identity. Our framework is based on the science identity framework developed by Carlone and Johnson for professional scientists [20]. Their framework has three dimensions. Hazari et al. adapted the framework for use with students by adding an additional dimension [5]. The original three dimensions are recognition, performance, and competence. Recognition describes to what extent the student feels that teachers, relatives, and peers see him or her as a "physics person." Performance refers to how capable the student feels at physics-specific tasks, such as test taking. Competence consists of the student's selfperceptions of his or her ability to understand physics. While performance and competence are closely related, they may be expected to differ in cases such as when a student does not expect to test well (solve formal problems) but feels they have an understanding of the concepts. However, previous work has found that the two dimensions are indistinguishable for most students [21,22]. The additional dimension is interest, or the student's desire to learn more about physics. The interest of professional scientists may be assumed. However, this is not the case for students.

Physics identity has been verified as a valuable framework for predicting physics career choice by Hazari et al. [5]. Further analysis has revealed that recognition and interest separately are significant predictors of physics career choice [21]. Furthermore, Hazari et al. found seven teaching strategies correlated with physics identity. One of them, discussing the underrepresentation of women in physics, was found to be a positive predictor of physics identity specifically for female students. This is consistent with work which used multivariate matching methods to test several proposed strategies to increase the number of women entering the physics career track: having a single-sex physics class, having women scientist guest speakers, having a female teacher, discussing the work of women scientists, and discussing the underrepresentation of women [6]. The only method found to have a significant effect was discussing underrepresentation. This work provides further details and explicates why discussions of underrepresentation may be important to consider. Specifically, we analyze in detail one teacher's methods for discussing underrepresentation.

\section{B. Figured worlds}

Figured worlds are socially and culturally constructed worlds that encompass the simplified, typical taken-forgranted stories or theories of how the world functions $[23,24]$. In these worlds, Holland et al. [23] explain that "particular characters and actors are recognized, significance is assigned to certain acts, and particular outcomes are valued over others." Figured worlds, including all associated values and assumptions, are unconscious.
They are "figured" by individual people and may change over time [24]. As identities form within figured worlds, they serve as a useful tool for understanding identity development [23]. Figured worlds overlap with other terms such as cultural worlds and communities of practice [24]. Communities of practice [25], in particular, are a type of figured world.

Figured worlds are mental simulations learned through experiences, both personal and vicarious through others and the media. The relationship between figured worlds and experiences is reciprocal. Experiences, while creating and changing figured worlds, are also colored by a person's preexisting figured world, as the figured world casts particular meaning on experiences. Additionally, how people perceive these experiences is influenced by the social and cultural groups they belong to. This reciprocal relationship may, at times, impede change. Experiences include discourse, events, and behaviors. The process of creating figured worlds is unconscious, but explicitly discussing the relevant experiences and associated typical stories may enable the figured worlds to change by bringing them to the conscious level [24]. As identities are situated and develop within these worlds, this then allows for the possibility of an identity shift.

As stated above, figured worlds are simplified models of the real world and lack much of its true complexity. They involve many assumptions, similar to a scientific model. This is partly out of necessity, as full understanding is difficult and time consuming. However, this simplicity may lead to marginalization and to the existence of power structures. Typical roles are expected of people, and certain behaviors and events are considered normal, while others are considered abnormal. The experiences that create and change figured worlds affect what is considered normal. People who are considered abnormal become marginalized. When figured worlds are brought to the conscious level, however, many will realize the shortcomings of the simplified model, and this can help to ameliorate the oppression and inequality the assumptions of the figured worlds may cause [24]. This is, in part, because examination of figured worlds may cause more roles to become available to play and more events and behaviors to become socially and culturally acceptable.

Education researchers have frequently used figured worlds to better understand how students and educators author identities in subjects ranging from literacy to mathematics and science [26-35]. In this work, we focus on the figured worlds both of school science and of the professional scientist. We seek to understand how classroom lessons explicitly discussing the underrepresentation of women in physics may change these figured worlds and thus physics identity. The class lesson brings to the surface the experiences that create these figured worlds. Figured worlds are used as a tool for analyzing discourse and for understanding identity. 


\section{METHODOLOGY}

The data used in this study are part of a larger project that seeks to identify and understand pedagogies that positively impact students' physics identities. The first phase of the project was a national survey of students in college English courses about their high school science experiences. Seven high school physics experiences were found to correlate with physics identity: focus on conceptual understanding, students teaching classmates, students making comments or answering questions, discussing science current events, discussing the benefits of being a scientists, labs that address real-world beliefs, and discussing the underrepresentation of women (for female students) [5]. In the second phase of the project, high school physics teachers who were reported to use at least four of these seven strategies by a student with a high physics identity were recruited. We conducted case studies of five teachers. Two of these five teachers were reported to discuss the underrepresentation of women, but only one teacher was able to describe such a lesson. In this paper, we focus on this teacher, Mr. S.

Mr. S taught physics and chemistry at a medium sized public school that served approximately 1500 students. His physics classes were a semester-long honors course and a year-long combination AP and IB course. The school population was predominately white $(84 \%) .31 \%$ of the students at this school were eligible for free or reduced lunch. He had taught high school physics for 15 years at the time of observations and has a bachelor's of science in a science field and a master's in science education. Mr. S was the only teacher in this study reported to satisfy all of the selection criteria.

Data were collected for two consecutive years. Two observers visited for a week during each year. Data included video recordings, field notes, student and teacher surveys, student and teacher interviews, and student work. Video was recorded by two cameras during the site visits. At the end of the site visit, the teacher was given one camera to collect video of key lessons for the remainder of the school year. In the first year of observations, the discussion of underrepresentation occurred after the site visit. In the second year of observations, the discussion took place on the last day of the site visit. Students were surveyed at the beginning of the site visits. The surveys were a shortened version of the national survey. Mr. S was given one survey prior to the site visits and a different survey following the site visits. The first survey collected information about scheduling, teacher background, and teaching strategies used. The second survey collected information about individual student's class participation and grades. Mr. S was interviewed during the middle of the site visits and by phone between the site visits. Because of the timing of the site visit during the first year of observations, student essays were not collected. However, student essays about women in physics were collected during the second year. Table I summarizes the primary and secondary sources of data used in this study. The primary sources of data were focused on in the analysis while the secondary sources were used for establishing the context.

The data were analyzed using a constant comparison method [36] with the purpose of developing theory on the mechanisms by which discussing the underrepresentation of women in science may impact physics identity and students' figured worlds. Examination of student essays revealed emerging themes which were discussed by the research team. Transcripts of the class discussion were inductively coded by identifying common topics of conversation and comparing sources of supports for claims. The codes fall within three broad classifications: topical categories of discussion, types of experiences, and attributes of figured worlds. The topical categories of discussion center on the subject of conversation; experiences are classified as either personal or vicarious; and attributes of figured worlds consist of typical stories, features, and, norms. The research team met to compare interpretations and to create and revise the codes. We compared across the codes and classifications to develop a theoretical understanding of their connections. Additionally, differences between student viewpoints described in the essays and elicited at different times during discussion were noted in order to gain insight into how students' perspectives may have shifted. In the next section, the themes emerging from the essays are described and the topical categories of discussion are described. Within the description of each topical category, we describe connections to the types of experiences and attributes of figured worlds.

\section{RESULTS}

\section{A. Overview of lesson-Setting the context}

The discussion of the underrepresentation of women took place in honors classes. Twenty students, 11 male and 9 female, were enrolled in the first year video recorded. In the second year, fifteen students, 8 male and 7 female,

TABLE I. Primary and secondary sources of data for this study.

\begin{tabular}{lccccc}
\hline \hline & \multicolumn{2}{c}{ Primary } & & \multicolumn{2}{c}{ Secondary } \\
\cline { 2 - 3 } Data source & $\begin{array}{c}\text { Student essays } \\
\text { prior to discussion }\end{array}$ & $\begin{array}{c}\text { Video or observation } \\
\text { of discussion }\end{array}$ & & $\begin{array}{c}\text { Teacher and student } \\
\text { surveys }\end{array}$ & $\begin{array}{c}\text { Teacher } \\
\text { interviews }\end{array}$ \\
\hline Year 1 & $\times$ & $\times$ & $\times$ & $\times$ \\
Year 2 & $\times$ & $\times$ & $\times$ \\
\hline \hline
\end{tabular}


were enrolled. Students completed surveys including questions about physics identity at the beginning of the site visit, prior to writing the essays about women in physics but after starting the reading assignment described next. Overall, male students reported significantly higher physics selfperceptions than their female counterparts $(p<0.001)$.

In the weeks leading up to the class discussion, the students read about early twentieth century physics in $E=m c^{2}:$ A biography of the world's most famous equation by David Bodanis. The students were assigned to write a four-paragraph essay that was due the day of the class discussion. This assignment is as follows:

(1) Describe the work of Lise Meitner, including her major contributions to science and the challenges she had to overcome.

(2) Describe the work of Cecilia Payne, including her major contributions to science and the challenges she had to overcome.

(3) Describe the work of Lisa Randall, including her major contributions to science and the challenges she had to overcome.

(4) Bring it all together/sum it all up. Is the opportunity to excel in physics any easier now than it was in the early 20th century?

The class discussion generally followed the format of this essay. The essays reflected students' existing figured worlds after having completed the reading but before the class discussion, while observations of the class discussion revealed experiences that create and modify the figured worlds of school science and professional science.

We have video of the classroom discussion from two separate years. All students in these classes have been assigned pseudonyms. Before delving into the details of the class discussion, we describe some major features of the two classes. In the first year of observations, the desks were arranged in groups of three or four. In the second year of observations, the desks were arranged into two sides facing each other. In both cases, the students selected their own seats. Desk arrangement in Mr. S's classroom often varied from day to day and even sometimes changed in the middle of class. The overall nature of the discussion was different in the two years as well. In the first year, students would often talk over each other and many students never spoke up enough for the whole class to hear. However, in the second year, speaking was more turn-based, and, on several occasions, Mr. S would ask a question and then go around the room and have everyone answer. It was still the case that some students spoke more than others, and some only participated in the brief moments when called on. The second year also seemed to feature more debate and be more student led compared to the first year. The discussion was overall more in-depth during the second year. Although we draw on data from both years, differences between the years are highlighted when relevant to the analysis and discussion.
In both years, the class discussion generally followed the same order as the essays. Mr. S asked the students to tell him about the three women physicists: Lise Meitner, Cecilia Payne, and Lisa Randall. The students responded with basic facts and the general stories of overcoming adversity. These stories represented vicarious experiences that helped to create the figured worlds of professional scientists. However, since the stories were focused on the past, this was not particularly relevant to how students saw themselves fitting into this world in the present day, though some students demonstrated interest in these stories. One student, Kelly, was passionate regarding the injustices that women of early 20th century physics faced, referring to one of the male scientists involved as a "jerk" repeatedly. In the second year, in particular, some of the students expressed a great deal of respect for these women. However, many students were less engaged during this part of the discussion. Evidence of student engagement is described in the next paragraph. This may have been a result of the stories being difficult for students to personally relate to because the women physicists chosen were depicted as exceptional. For example, when Mr. S asked why Lisa Randall got on Time Magazine, students responded that "She's smart" and "First physics woman [on Time]" to which Mr. S responded, "So yeah, a lot of firsts for her."

The remainder of the discussion in both years focused more on present day. We found that students were more engaged at this point, when the conversation was relevant to their own lives, and hence more connected to the figured worlds of the present. In the first year, this was evidenced by the students visibly talking more. In many cases, the exact nature of what the students were saying was inaudible. Many of the students, especially the girls, would speak quietly with their neighbors. At other times, many students would talk at once, what Mr. S described as a "dull roar." The increased engagement in the second year was evidenced by the enthusiasm of the students to speak and the increased debate. There may not have been as much near-neighbor discussion because of the desk arrangement.

\section{B. Prior beliefs}

We gained insights into the students' prior beliefs and features of their existing figured worlds through their essays. The students wrote four paragraphs as assigned. The first three paragraphs focused on the three particular women physicists were mostly factual and revealed minimal insight into the students' viewpoints of women in physics. The revealing part of the essays was the fourth paragraph where the students were prompted to write about the comparison of present day to the early 20th century. While this represented their beliefs prior to the class discussion, it is likely that they had already begun increasing their complexity of thought by reflecting on their own ideas (bringing their figured worlds to the conscious level) through the process of reading the assigned book and writing the essays. Many of their essays 
TABLE II. Prior beliefs exhibited in essays.

\begin{tabular}{lc}
\hline \hline Category & Example \\
\hline Theme of overcoming obstacles & $\begin{array}{c}\text { Women have come a long way in terms of overcoming a barrier of prejudices and discrimination, } \\
\text { and as they still fight this uphill battle in many ways, it is the work of women like these that } \\
\text { encourage other female physicists and help pave their way to success in the science world. -Joe } \\
\text { The opportunity for women to excel in physics today is defiantly easier now than it was in the early } \\
\text { 20th century. More women physicists are being recognized for their achievements in science } \\
\text { along with the fact that science officials are going back in history and giving recognition to } \\
\text { whatever men can } \\
\text { wemen that played a crucial role is discoveries and never were given the recognition they }\end{array}$ \\
\hline \hline
\end{tabular}

demonstrated that the reading had influenced their thoughts. For example, Susan wrote, “...it is valid to say that it has not always been this way just by reading and hearing for the first time about Lise Meitner and Cecilia Payne...," and Teresa wrote, "Comparing these women's restraints to the seemingly nonexistent ones of Lisa Randall, it can be seen how..." Two major themes emerged: one of overcoming obstacles and one that women can now accomplish whatever men can. Several students, in fact, used the word "overcome." Table II illustrates these themes. These represent the shared cultural stories that make up figured worlds of professional scientists.

These two themes may have arisen because of the focus on early 20th century physics in the question and encouraged by the reading assignment. This may have caused the problems of inequality of the past to seem to dwarf current problems, as present-day gender inequality may be of a subtler nature. For example, Tammy wrote,

Compared to previous views of women, especially during the early 20th century, today there aren't many restrictions placed on women and what they are considered able to do and accomplish.

Gail's optimistic observation shown in Table II also reflects how the focus on the past had made present-day struggles seem minor. Interestingly, Roy championed women's progress in a similar manner as Tammy and Gail while simultaneously using patriarchal language:

Throughout time, people (men, rather) have thought of women as no more than good companions who couldn't possibly aid in the fields of science and math. That is a sad misconception. This theory has been undoubtedly crushed the role many women have played in explaining the way our world, and perhaps other worlds, work. The creatures of the opposite gender have been terrific partners in the search for truth and are indeed a gift to be treasured. [Emphasis added]

This suggests that Roy consciously believed in gender equality and that much progress had been achieved, but his language indicated that unconsciously he still may be objectifying women. These unconscious word choices reflected his figured world of professional science.

Though many students' essays showed evidence that their figured worlds of professional science consisted of stories of women having overcome adversity in the past and achieving greater equality in the present, a few observed that inequalities persist today. For example, Emily wrote,

I know that men are quick to shun down an idea from a woman just because it is from a woman. Boys are very quick to make me feel horrible for an idea I have but will turn around and take credit for the exact idea I have come up with.

Another student, Susan, included several examples of present-day inequalities in her essay. These included a "describe a scientist" activity in which students were asked to draw what they think a scientist looks like during one of her other courses, how students split into lab groups in AP Biology class, experts on Oprah, and the efforts colleges put into recruiting women into science. In contrast to many of the other essays, Emily and Susan described more personal and concrete experiences that have shaped their views.

TABLE III. Categories of discussion topics.

\begin{tabular}{ll}
\hline \hline Category & Example \\
\hline Famous scientists & ..I think of Jane Goodall. And it was um, why uh, how ya know the uh gorilla travel in a pack, it how does it. \\
& A guy, ya know, think Albert Einstein you think why does $E=m c^{2}$. -Michael \\
Gendered & But um I feel like if women are in a particular role in science I don't think it's because women are a certain way. \\
professions & I think it anything it's like nurture versus nature, like we're pushed into a certain role rather than us \\
like preferring nursing. -Kelly \\
experiences
\end{tabular}


The stories of their figured worlds applied to school science rather than only professional scientists. These observations of inequality were not limited to the female students however. One male student, Logan, observed, “...I think there will always be an underlying, subconscious for most that men are more 'scientific'." Another student, Joe, observed that women "still fight this uphill battle in many ways."

The final paragraphs of the essays revealed the features of the students' figured worlds of school science and professional science and what roles women play in these worlds prior to the class discussion. Although most students felt that women can now accomplish whatever men can in science, a few students believed that inequalities persisted, especially those students who had more concrete personal experiences with inequality. Regardless, the essays suggest that this lesson, even before the class discussion began, prompted thought from the students with regards to gender issues in physics. As will be seen in the next section, the classroom discussion pushed them further, as they were then exposed to their fellow classmates' viewpoints and experiences.

\section{Topical categories of discussion}

The class discussion may have created opportunities for figured worlds and thus identities to change by bringing the experiences that had created students' figured worlds and the characteristics of these figured worlds to the conscious level. During the discussion, students described the features of their figured worlds and experiences that created those worlds. The primary worlds to consider were those of school science and of professional science. Students participated in the world of school science and sometimes saw potential for themselves to participate in the world of professional science. The classroom discussion was coded by the subject of conversation. These topical categories of discussion are listed in Table III. In the following, each category is illustrated with several excerpts from the class discussion, and the connections to the types of experiences and attributes of figured worlds are described. As shown in Fig. 1, the categories related to students' experiences, both personal and vicarious, that served to create and expand the figured worlds of students and also connected to the typical stories, features, and norms of the figured worlds. In the figure, three types of lines originate on the topical categories of discussion: dashed lines connect to vicarious experiences, dotted lines connect to personal experiences, and solid lines connect directly to figured worlds. Lines with double arrowheads connect experiences and figured worlds in order to show their reciprocal relationship.

\section{Famous scientists}

Frequently, students grounded their ideas in narratives that were created through the vicarious experiences of famous scientists, either historical or present day. With the exception of Jane Goodall, all the scientists mentioned

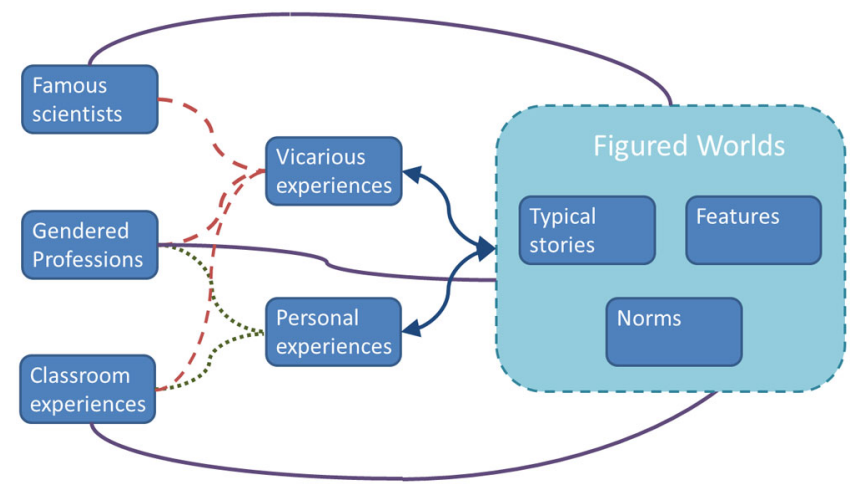

FIG. 1. Schematic of the relationship between the topical categories of discussion, types of experiences, and attributes of figured worlds. The topical categories of discussion are connected to types of experiences by two types of line: The dashed lines connect topical categories to vicarious experiences, and the dotted lines connect the topical categories to personal experiences. Additionally, solid lines connect topical categories directly to attributes of figured worlds. Types of experiences and attributes of figured worlds are connected by lines with double arrowheads in order to represent their reciprocal relationship.

were part of the assigned reading. The stories of the famous scientists explicate the typical stories, features, and norms of the world of professional science. Figure 1 shows how this category connects to the figured worlds framework.

In one instance, Michael used Lisa Randall's success to support his claim that

It doesn't really matter if you're, what the sex, what the gender is, or if the idea's just too farfetched as long as it makes sense.

Lisa Randall's career served as a vicarious experience which helped to create Michael's figured world of professional science. In another example, Linda stated, “...if you would ask me the name the first woman in science that you think of, I would think of like Jane Goodall." Mr. S proceeded to respond to her discussion of chimpanzees with a reference to "warm fuzzy things." This exchange suggested that some fields of science may be considered feminine and thus demonstrates the surfacing of the norms and features of their figured worlds. The lives of the three women physicist examples supported the formation of a figured world typified by narratives in which impressive individuals overcome obstacles, and society does not need to change. This is exhibited by the claims of both Kelly and Linda. Kelly described how Lise Meitner and Cecilia Payne were able to accomplish a great deal and concluded,

I feel like now, their, a woman's opinions can be respected because these women were able to do that because of the fact that they were able to do it back then.

Linda used the success of these women physicists to support her claim: 
...everyone has the ability to do something and make a name for themselves and kind of like create their own ideas about stuff. Um, it just matters who takes the initiative to actually do it.

She espoused the viewpoint that gender equality is up to the individual rather than society. Kelly felt the story of science is about the ability to break rules, in large part because of Cecilia Payne's findings going against the standard theories of her time. This was revealed in her ideas when discussing working in a controversial area of science,

Like I feel like now, like things like that would be more led by men just because they might feel like their opinions would be more respected and women wouldn't be as respected to against it still.

Of note is that this was a shift from the beliefs she supported in her essay and even at other points during the discussion where she claimed that gender equality had been achieved.

Michael arrived at surprising ideas based on his interpretation of the careers of Jane Goodall and Albert Einstein. He built off of Linda's earlier comment about Jane Goodall and off of the assigned reading,

What I want to go with is I just think women want to find out the inner makings of something, what makes something work, where men just want to find out why it works.

This claim prompted immediate disagreement from Linda, "I want to know why it works." Michael explained somewhat unexpectedly,

...I think of Jane Goodall. And it was um, why uh, how ya know the uh gorilla travel in a pack, it how does it. A guy, ya know, think Albert Einstein you think why does $E=m c^{2}$.

The important part of this exchange was the conflict it created between the two students. They both likely realized that their figured worlds of women in science contrast (though they would not use such terms). The present experience of discussing their viewpoints may have enabled change to both of their figured worlds and place in those worlds (i.e., identities). For example, Linda, through better understanding Michael's opinions, may not respect his claims in future, thus preventing Michael from making Linda feel that she does not fit in physics class.

\section{Gendered professions}

The students discussed the gendered nature of several professions expanding their focus beyond science. This included discussing how scientists are depicted on television. They also transitioned to exploring the role of the individual versus the role of society in women's career choices. As shown in Fig. 1, discussing the gendered nature of professions involved describing the personal and vicarious experiences that created figured worlds and also describing the norms, typical stories, and features that make up figured worlds.

In both years, the students discussed the medical profession and how there are many women in nursing. Additionally, the class discussed the difficulties men may encounter in "assistant" professions such as technician or nurse. Mr. S described how his parents use the term "lady doctor." Similarly, when Linda used the term "male nurse," Mr. S highlighted her phrasing. That these terms have an explicit gender component indicates that the terms have a default gender, the opposite gender. The power dynamics associated with these terms became explicit when Susan claimed, "Doctors is better than nursing," prompting Mr. S to tease her for insulting a whole profession. The exchange emphasized that being a doctor, the by-default male profession, is valued above being a nurse, the by-default female profession. Though it is likely that most students were vaguely aware of these power structures, making them explicit may have made it possible to question these taken-for-granted assumptions. That certain professions have "default" genders may also have brought into focus how people may be made to feel uncomfortable in certain professions.

Significant portions of the discussions focused on the differences between specific academic disciplines. In response to Mr. S asking the girls if they feel like they have to struggle more, Martha responded, "It matters what field you're going into I think." After prompting, she elaborated,

Like, for me, I'm going into psychology, and people don't really think about it because we like empathize with people, but if I was going into a physicist like or a mathematician, then people would probably see me like what you're actually smart enough for that?

Importantly, she brought up the issues that some may not see women as smart enough for physics or math, and that women are more focused on the realm of emotion. These were features of the simplified figured worlds of both school science and professional science rising to the conscious level prompting further examination. However, the class did not discuss this further. Additionally, Mr. S asked the class specifically about physics and engineering. Andrew responded, "I think that's a man's science." This was met by loud cheering and excitement from most of the male students. Again, this is a feature of the students' figured world becoming explicit. However, neither Mr. S nor any of the other students challenged this claim or asked why. Very frequently in the first year of observations, claims would go unchallenged and unexplored, so any examination would take place either silently or outside of class, if at all, in contrast to the second year of observations. 
Mr. S also initiated a conversation about how scientists are portrayed in popular media, emphasizing the role of women. He started this discussion in both the first and second years of observation. In both years, this portion of the conversation was particularly teacher rather than student focused. The shows featuring scientists brought up included NCIS, Bones, and Scrubs. Mr. S elaborated with the most detail when describing Big Bang Theory, the show about three physicists and an engineer, all men. Most of the women on the show are biologists. He explained how one of the actresses who plays a biologist actually has a $\mathrm{Ph} . \mathrm{D}$. in biology. He also explained that one of the actresses who plays a forensic scientist on NCIS really has a degree in forensic science. This part of the discussion brought to the forefront the vicarious experiences in the media that contributed to the creation of the figured worlds of professional scientists.

During the discussion of specific fields of science and whether some fields attracted more women than others, the features and typical stories of the figured world of professional scientists became explicit. Through making these stories overt, some of the students came to consider whether the reason behind the gender differences is the individual or society. For example, Gail observed that “... they [women] still don't get the same respect as men do in certain fields..." When Mr. S asked her if that motivated her to go into a certain field, she responded that "I just think it's important like especially for more girls to take more initiative and get out there and do something...." She puts the onus on women to change rather than on society. This exchange led into more explicit discussion on the role of society versus the role of the individual. This constitutes part of the typical stories of how people make their career decisions. Two female students expressed opposing viewpoints. Kelly stated,

But um I feel like if women are in a particular role in science I don't think it's because women are a certain way. I think if anything it's like nurture versus nature, like we're pushed into a certain role rather than us like preferring nursing.

Gail argued,

I just think that like compared to guys women are just like naturally more nurturing kind of like motherly, know what I mean? So obviously they're gonna like tend to draw more to like animals and things like that.

This disagreement about how the world functions was particularly important because it may have prompted both students to reexamine their viewpoints and increase the complexity of their figured worlds. Mr. S pulled this discussion back to the concrete by interpreting the fields women would be drawn to,
Well when you said the more nurture thing, you mean the more fields like medicine and biological sciences and less towards geology, physics and less humanistic science.

This clarification may have served the purpose of helping the students to connect the very general observations about nurture versus nature to specific career-related decisions. Nurture represents one typical story of how people become who they are and make their career decisions, while nature represents another. In this exchange, the different typical stories show the differences between each students' figured world.

\section{Classroom experiences}

In addition, students discussed their classroom experiences. These experiences were primarily personal, but vicarious experiences were also included. They also described the norms and features of the figured worlds of science as shown in Fig. 1. For example, the distribution of genders in teaching and in college majors were both discussed. Students have many personal and vicarious experiences to relate to these topics. In the first year, Mr. S prompted the students to note the genders of their teachers and how that varied by subject. As was common during the first year discussion, the reasons behind were not explored. They also talked about the hierarchy of subjects at the college level, and Mr. S brought in his personal college experiences of which majors had more women in them. The existing distributions of men and women in various fields may have explicated what is considered "normal," while the discussion of hierarchy emphasized the existence of power structures.

In another instance, Susan described a drawing activity from another class, as she did in her essay, to explain the existence of stereotypes,

...you wanted us to draw scientists and we had to put them on the board and it was like there's this deep rooted stereotype that scientists are male and have crazy hair and wear a labcoat and...there were like six groups; we all put out things on the board and there wasn't like one woman on the picture.

Susan's personal experience reflected how she and her classmates figured the world of professional scientists. Additionally, Susan described the experience of her friend's sister to explain why women might choose certain fields where they would feel more comfortable:

She's going to school to be a biochemical engineer and she says that when she goes into classes and she's the only girl, she doesn't want to feel discouraged, but it's hard not to. 
This friend provided vicarious experiences for Susan. These experiences were likely colored by and reinforced her preexisting discouragement.

Kyle built on his own experience in physics class but also incorporated ideas from a recent personal experience with one of his classmates (and girlfriend), Linda. He explained,

I guess it's just cause I'm a guy. Sports and all that stuff. I like the way they [physics] can explain how a football's going. But like I know for like women would rather do something more noble like saving a puppy's life.

He did not describe all of the experiences that led to his ideas. However, Linda elaborated that he mentioned saving a puppy because she made him save a turtle recently.

Interestingly, the students discussed their immediate personal experience. During the first year of conversation, students observed a feature of their own physics classroom allowing them to examine their personal experiences that create the figured world of school science. Samuel observed, "We're split up, like into two different..." Mr. S supported his observation,

I was about, I'm glad you noticed that; I was about to ask, I wanna know who's fault is there, and look at yourselves. Look at this room.

What they had noticed is that the boys sat on one side of the room, while girls sat on the other side of the room. The students had self-segregated. Mr. S pointed out that there were no assigned seats and made a joke about cooties. Mr. S probed them about why this had happened. Samuel responded,

I don't know. It's easier to relate with the, uh, when you're talking and you're experimenting, or doing lab, it's easier to relate with the same gender. I don't know. I, for me, like, it's easier to talk about, like, lab stuff, and just go, like, I don't know. I can't. Girls I have trouble working. It's easier to work. You can't relate.

This caused Amanda to argue, "That's social skills, that's not like..." Samuel became defensive, "I have got social skills, okay." The students continued discussing possible reasons. The incoherency of Samuel's explanation may have reflected that he had not given the issue any thought and that the self-segregation was taken for granted. Bringing these issues to the surface may prompt increasing complexity of thought. This segment of the conversation may have caused the students to realize that there really are gender differences. This is especially important because throughout childhood many students may have been told that everyone is equal and that girls can do anything boys can do [19]. This view of equality was evident in many of the students' essays collected in the second year. Important to note is that this is one of the few topics that created conflict during the first year conversation.

\section{Linking categories to student experiences and figured worlds}

The classroom discussion was divided into several categories as described in the previous section (famous scientists, gendered professions, classroom experiences). To explore the potential impact of each topic of conversation, the relationship of each of these categories to students' figured worlds of school science and professional science was examined. We linked each category to the type of student experience it was drawn from (personal experience the student had themselves or vicarious experience of someone that student knew about). We additionally tied the categories and experiences to important aspects of students' figured worlds: typical stories, features (characteristics), and norms (values and assumptions) [19]. The connection between experiences and figured worlds is an important one since they have a reciprocal relationship, i.e., experiences shape and change figured worlds and figured worlds color and provide interpretations for new experiences. However, the categories were not all related to figured worlds through experience; the relationships were also based on students' personal ideas not tied to a "conscious" experience but more likely a result of socialized implicit beliefs. This direct connection between students' ideas and their figured worlds is important because these ideas serve to reproduce identities within a culture [20]. A schematic of these relationships is shown in Fig. 1.

Most of the students who raised conflicting views or experienced frustration during the discussion were ones for whom a more conscious link to personal or vicarious experiences became apparent (e.g., Linda, Gail, Susan, Kelly, Samuel) while those who made a weaker tie to experience and mostly described personal ideas (shown by direct paths between categories and figured worlds; reflecting general features of their figured worlds) did not pose conflicting viewpoints (e.g., Kyle, Michael)—they were not challenging the boundaries of their figured worlds. While these students may have been aware of the experiences that led to their beliefs, they did not make an explicit connection. One possibility is that they were operating from some sense of the world where they were not conscious of the connection. Bringing experiences and beliefs to the conscious level can allow figured worlds to change [24]. However, without becoming conscious of the experiences that lead to a particular figured world, particularly if that figured world is a more prevailing view of the world (e.g., girls can do anything boys can do regardless of barriers or hurdles-but maybe they choose not to), it would be difficult for these students' figured worlds to change. On the other hand, for a student like Samuel who was making connections to personal experience (the fact that the class had gender segregated), there was likely more opportunity to change his figured world as evidenced in the 
conflict he later expressed when he felt that males were being labeled with having fewer "social skills."

In sum, the connections in Fig. 1 are important because figured worlds influence how students view their own experiences and their own connections to physics and science in general - either they uphold normative identities or begin to reimagine identities with an expanding or changing figured world. While the categories of gendered professions and classroom experiences were both elaborated by some students through personal experiences, famous scientists was not. However, all three categories were elaborated on through vicarious experiences. These experiences served to explicate the typical stories that constituted students' figured worlds (e.g., portrayal of women in certain professions) and also connected to cultural norms that are part of figured worlds (e.g., women are expected to be nurturing). Students who did not articulate these experiences described their personal ideas that were very general features of students' figured worlds (e.g., boys like sports, girls like animals) that were not given very much dedicated thought.

\section{DISCUSSION}

Each of the categories of discussion may have provided impetus for the students' figured worlds to change. Eliciting the experiences, both personal and vicarious, that created the figured worlds allowed the students the opportunity to examine the origin of their beliefs. Describing the features and norms of figured worlds likely caused them to think about their simplified worlds in a more complex manner. Hence, each student's conceptualization of how women fit into school science and professional science had the opportunity to change. The features of students' worlds prior to the class discussion were evident in their essays. The mechanism for change was suggested by students' conversations.

Experiences create figured worlds, but the relationship is also reciprocal [23,24]. Figured worlds, in turn, color experiences. Students' views of the world influence how they interpret life events. These life events and experiences are crucial to identity development [5]. For an experience to lead to recognition as a physics person, interest in physics, or perceptions of performance and competence, the student's figured worlds must be supportive. The class discussion of underrepresentation provided an opportunity for the figured worlds of school science and professional science to change. Hence, students' past experiences were cast in a different light, and thus, they will view future experiences in new ways. An experience that previously may not have led to an increase in physics identity may now have an effect. For example, a student may have previously viewed physics as a discipline only appropriate for men; that is, the "default" physicist would have been a man. The student may then limit the effect of her experiences of being successful in physics class to her good student identity rather than allowing any effect on her physics identity or her career interests and aspirations. A discussion that expands the view of who can be a physicist, what it means to be a physicist, and challenges the norms of the figured worlds of science then allows these experiences to have an impact on the student's physics identity and career aspirations as well. In other words, a change in a student's figured worlds of school and professional science can alter students' interpretations of their experiences in physics. Because students' perceptions of these experiences are integral to every dimension of identity development, their physics identity may then shift given similar experiences as before (since they are interpreted in a new light).

An additional important aspect of this class discussion to emphasize was when students disagreed with each other. This occurred within almost every category of discussion: Kelly and Gail disagreed about "nurture versus nature"; Michael and Susan disagreed about whether equality has been achieved; Linda disagreed with Michael about whether women want to understand why something works; Amanda and Samuel argued about social skills. Disagreement happened more frequently and clearly in the second year of observations than the first. Importantly, the disagreements likely caused all students to examine the features of their figured worlds more closely. If everyone agreed, no one would need to consider the basis for their beliefs about how the world functions. Kelly's beliefs were often in conflict with another female student's beliefs, Gail's, and two of the male students, Michael and Kyle. This may also have empowered Kelly and caused her to change her way of viewing Michael and Kyle and anything they might say in the future. Disagreement was much less frequent in the first year of observations. That conversation involved multiple students talking at once, whereas the second year discussion featured more individual viewpoints which seemed to be more effective at revealing the boundaries of individual students' figured worlds (through conflict) thereby creating an opportunity to expand these worlds.

One other important attribute of this lesson is that it contrasts with typical physics class activities. Students are accustomed to taking notes, working problems, and performing labs. Writing an essay and having a class discussion is not typical for a high school physics class. Hence, this experience can also serve to alter the figured world of school science by adding a new type of activity, one that makes physics class more comfortable for certain students. This may also be uncomfortable for the students that prefer the typical physics class activities. Additionally, students appeared to take greater interest and engage in the conversation more when the topics discussed became more personally relevant. Engagement was relatively low when discussing historical figures but increased when discussing the present day and personal views. Evidence for increased engagement included an increase in students talking and 
multiple students talking at once in year 1 and increased debate in year 2. This is particularly important since students have been found to see physics as narrow and lacking autonomy of thinking [37]. In addition, students have been found to have little personal interest in physics with this interest declining even further after taking a physics class $[38,39]$. Thus, understanding the ways in which we can expand the boundaries of their figured worlds to include interests they may not have considered before may provide a pathway to engaging students in learning physics beyond a single physics class.

\section{CONCLUSION}

Understanding methods to increase female students' physics identities is important for closing the gender gap in physics. We have examined one teacher's lesson in detail in order to examine the possible mechanisms by which a class discussion on the underrepresentation of women in physics may impact students' figured worlds and subsequently their physics identity. While the discussion was grounded in the life and work of notable female physicists, the part of the discussion with the greatest apparent impact focused on the experiences of women in both school science and professional science today. When discussing the present day, the discussion likely became more personally meaningful for the students. This personal relevance (which likely generated interest) and the recognition they received for their opinions during the discussion may have also played an important role for physics identity development since interest and recognition are the cornerstones of identity development.

Future implementations of the discussion of underrepresentation may improve upon the lesson described in this case study in several ways. One method that may improve this lesson is to decrease the reliance on historical physicists and even on famous modern-day physicists. The injustices confronted by female scientists of the past may dwarf the subtler inequalities of the present day. In contrast to the treatment of women of the past, the issues that women face today may seem less important. This is primarily evidenced by the common themes exhibited in students' essays of overcoming obstacles and achieving higher levels of equality. Both the famous historical physicists and the modern-day physicist may be difficult for students to relate to because they are portrayed as exceptional. Thus, students may not be able to envision themselves as able to overcome similar challenges and may feel unable to become a participant in the world of professional science. However, historical physicists may still need to be included in future implementations in order to connect the lesson to state science standards. Furthermore, another possible modification to the lesson is for the teacher to prompt students to explain their reasoning or to follow up on the students' claims more regularly. The contrast between the year 1 and year 2 discussions emphasizes the importance of challenging claims and asking for elaboration. Students voiced their disagreements with each other more actively during year 2 . The effect was a more in depth discussion. Students during year 1 were less willing to challenge each other. The need for teacher intervention may vary considerably between classes. With more reticent students, the teacher may need to prompt deeper reflection more frequently.

While this work provides insight into the mechanism of how discussing underrepresentation of women in science may lead to an increase in physics identity for female students and how such a lesson may be implemented, more work is needed to develop an optimized lesson for high school classes based on our findings. The quantitative impact of the discussion of underrepresentation on physics identity and career interests has already been demonstrated $[5,6]$ although not explicitly for this lesson. Thus, the results of the current work are not generalizable or confirmatory even though the teacher was selected due to his ability to inspire students to be physics majors as well as his being reported by a student to discuss underrepresentation. Fortunately, producing generalizable results was not our intent since the goal was to understand the possible explanatory mechanisms and build theory as to why such discussions might impact women's physics identities. Our future work will focus on developing a specific lesson plan and measuring its impact on physics identity in more systematic ways across high school classrooms. Our previous work implementing a homework assignment involving a reading about the discussion of underrepresentation of women in science found no significant effect on physics identity [40]. However, the context differed in that the student population consisted of college students who had already opted out of physics and engineering, rather than high school students, many of whom have yet to select a college major. Additionally, a homework assignment given in a large lecture class should not be expected to have the same impact as a discussion in a small class, particularly since the most valuable aspects occurred as a result of the expression of personal and vicarious experiences.

This study revealed that discussing the underrepresentation of women in science explicitly created an opportunity for students' figured worlds of professional and school science to change, and therefore, may have altered the ways that students interpret their own experiences. These altered views pave the way for more experiences to contribute to a student's sense of self as a physics person. The potential change in figured worlds and physics identity is most important for female students. That the students may have begun to challenge their own implicit assumptions about how the world functions means that the norms in students' figured worlds may change or become less rigid. Their worlds, particularly on the subconscious level, may more easily accept girls who show interest in physics 
or women as physicists. Consequently, female students may view more of their personal experiences in ways that contribute to physics identity and may come to view themselves as potential participants in the world of professional science and the world of professional physics, more specifically.

\section{ACKNOWLEDGMENTS}

This material is based on work supported by the National Science Foundation under Grant No. 1431846. We would like to thank our participating teacher and his students for sharing their classrooms and experiences with us.
[1] U.S. Department of Education, National Center for Education Statistics, Integrated Postsecondary Education Data System (IPEDS), Fall 2011, Completions component. (This table was prepared June 2012.).

[2] P. J. Mulvey and S. Nicholson, Physics bachelor's degrees: Results from the 2010 survey of enrollments and degrees, Focus On, American Institute of Physics Research Center (American Institute of Physics, College Park, 2012).

[3] S. White and C. L. Tesfaye, Female students in high school physics: Results from the 2008-09 nationwide survey of high school physics teachers, Focus On, American Institute of Physics Research Center (American Institute of Physics, College Park, 2011).

[4] R. Ivie and S. Guo, Women physicists speak again, AIP Conf. Proc. 749, 179 (2005).

[5] Z. Hazari, G. Sonnert, P. M. Sadler, and M.-C. Shanahan, Connecting high school physics experiences, outcome expectations, physics identity, and physics career choice: A gender study, J. Res. Sci. Teach. 47, 978 (2010).

[6] Z. Hazari, G. Potvin, R. M. Lock, F. Lung, G. Sonnert, and P. M. Sadler, Factors that affect the physical science career interest of female students: Testing five common hypotheses, Phys. Rev. ST Phys. Educ. Res. 9, 020115 (2013).

[7] K. Scantlebury and D. Baker, in Handbook of Research on Science Education, edited by S. Abell and N. Lederman (Lawrence Erlbaum, Mahwah, NJ, 2007), pp. 257-286.

[8] K. Due, Who is the competent physics student? A study of students' positions and social interaction in small-group discussions, Cult. Stud. Sci. Educ. 9, 441 (2014).

[9] P. Heller and M. Hollabaugh, Teaching problem solving through cooperative grouping. Part 2: Designing problems and structuring groups, Am. J. Phys. 60, 637 (1992).

[10] P. W. Laws, P. J. Rosborough, and F. J. Poodry, Women's responses to an activity-based introductory physics program, Am. J. Phys. 67, S32 (1999).

[11] S. J. Ceci and W. M. Williams, Understanding current causes of women's underrepresentation in science, Proc. Natl. Acad. Sci. U.S.A. 108, 3157 (2011).

[12] B. J. Guzzetti and W. O. Williams, Gender, text, and discussion: Examining intellectual safety in the science classroom, J. Res. Sci. Teach. 33, 5 (1996).

[13] S. Jones and D. Myhill, "Troublesome boys" and "compliant girls": Gender identity and perceptions of achievement and underachievement, Br. J. Sociol. Educ. 25, 547 (2004).

[14] H. Stadler, R. Duit, and G. Benke, Do boys and girls understand physics differently?, Phys. Educ. 35, 417 (2000).
[15] U. Kessels, Fitting into the stereotype: How genderstereotyped perceptions of prototypic peers relate to liking for school subjects, Eur. J. Psychol. Educ. 20, 309 (2005).

[16] P. Murphy, S. Lunn, and H. Jones, The impact of authentic learning on students' engagement with physics, Curric. J. 17, 229 (2006).

[17] C. M. Brody et al., Gender Consciousness and Privilege (Falmer Press, London, 2000).

[18] L. Bierema, The role of gender consciousness in challenging patriarchy, Int. J. Lifelong Educ. 22, 3 (2003).

[19] B. Francis, The Gendered Subject: Students' subject preferences and discussions of gender and subject ability, Oxf. Ref. Educ. 26, 35 (2000).

[20] H. B. Carlone and A. Johnson, Understanding the science experiences of successful women of color: Science identity as an analytic lens, J. Res. Sci. Teach. 44, 1187 (2007).

[21] R. M. Lock, Z. Hazari, and G. Potvin, Physics career intentions: The effect of physics identity, math identity, and gender, AIP Conf. Proc. 1513, 262 (2013).

[22] J. D. Cribbs, Z. Hazari, P. M. Sadler, and G. Sonnert, Development of an explanatory framework for mathematics identity, in Proceedings from the 34th PME Conference, edited by L. R. Van Zoest, J.-J. Lo, and J. L. Kratky (Western Michigan Univ., Kalamazoo, MI, 2012), p. 335.

[23] D. Holland, W. Lachiotte, Jr., D. Skinner, and C. Cain, Identity and Agency in Cultural Worlds (Harvard University Press, Cambridge, MA, 1998).

[24] J.P. Gee, How to Do Discourse Analysis (Routledge, New York, 2011)

[25] E. Wenger, Communities of Practice: Learning, Meaning, and Identity (Cambridge University Press, New York, 1998).

[26] L. Urrieta, Jr., Figured worlds and education: An introduction to the special issue, Urban Rev. 39, 107 (2007).

[27] L. Urrieta, Jr., Identity production in figured worlds: How some Mexican Americans become Chicana/o activist educators, Urban Rev. 39, 117 (2007).

[28] E. Tan and A. C. Barton, Unpacking science for all through the lens of identities-in-practice: The stories of Amelia and Ginny, Cult. Stud. Sci. Educ. 3, 43 (2008).

[29] M. V. Blackburn, Losing, finding, and making space for activism through literacy performances and identity work, Penn GSE Perspectives on Urban Education 2, 1 (2003).

[30] D. Dagenais, E. Day, and K. Toohey, A multilingual child's literacy practices and contrasting identities in the figured worlds of french immersion classrooms, Int. J. Biling. Educ. Biling. 9, 205 (2006). 
[31] A.S. Jurow, Shifting engagements in figured worlds: Middle school mathematics students' participation in an architectural design project, J. Learn. Sci. 14, 35 (2005).

[32] K. M. Leander, Locating Latanya: The situated production of identity artifacts in classroom interaction, Res. Teach. Engl. 37, 198 (2002).

[33] W. Luttrell and C. Parker, High school students' literacy practices and identities, and the figured world of school, J. Res. Read. 24, 235 (2001).

[34] B. Street, What's "new" in new literacy studies? Critical approaches to literacy in theory and practice, Curr. Issues Comp. Educ. 5, 77 (2003).

[35] B. Fecho, P. Graham, and S. Hudson-Ross, Appreciating the wobble: Teacher research, professional development, and figured worlds, Engl. Educ. 37, 174 (2005).

[36] B. G. Glaser and A. L. Strauss, The Discovery of Grounded Theory: Strategies for Qualitative Research (Aldine Transaction, New Brunswick, 1999).
[37] U. Kessels, M. Rau, and B. Hannover, What goes well with physics? Measuring and altering the image of science, Br. J. Educ. Psychol. 76, 761 (2006).

[38] W. K. Adams, K. K. Perkins, N. S. Podolefsky, M. Dubson, N. D. Finkelstein, and C. E. Wieman, New instrument for measuring student beliefs about physics and learning physics: The colorado learning attitudes about science survey, Phys. Rev. ST Phys. Educ. Res. 2, 010101 (2006).

[39] R. F. Moll and M. Milner-Bolotin, The effect of interactive lecture experiments on student academic achievement and attitudes towards physics, Can. J. Phys. 87, 917 (2009).

[40] G. Potvin, Z. Hazari, and R. M. Lock, Exposure to underrepresentation discussion: The impacts on women's attitudes and identities, 2014 PERC Proceedings, Minneapolis, MN, 2013 edited by P. V. Engelhardt, A. D. Churukian, and D. L. Jones (American Association of Physics Teachers, Maryland, 2014). 